\title{
Manejo de novilhas prenhes aos 13/15 meses de idade em sistemas a pasto
}

\author{
Alcides Pilau ${ }^{1}$, José Fernando Piva Lobato ${ }^{2}$ \\ 1 Programa de Pós-Graduação em Zootecnia - Faculdade de Agronomia - UFRGS. Bolsista CNPq. \\ 2 Departamento de Zootecnia, Faculdade de Agronomia - UFRGS. Bolsista IA CNPq, Caixa Postal 15100, CEP: 90001-970, Porto Alegre, RS.
}

RESUMO - O trabalho foi realizado para avaliar o desenvolvimento de 32 novilhas primíparas gestantes Aberdeen Angus e mestiças Angus recriadas e acasaladas dos 13 aos 15 meses de idade. O experimento teve início no diagnóstico de gestação pela técnica de ultra-sonografia, realizado 28 dias após o término do período reprodutivo. O peso vivo (PV) inicial médio foi de $288 \mathrm{~kg}$ e a condição corporal (CC) inicial média de 3,2 pontos. Nesta ocasião, as novilhas foram distribuídas uniformemente por grupo genético, peso e ordem de concepção em dois sistemas de pastejo. Os sistemas de pastejo foram: PMI - novilhas prenhes mantidas na fase inicial de gestação em pastagem de milheto (Pennisetum americanum, L.); PNA - novilhas prenhes mantidas na fase inicial de gestação em pastagem natural. O pastejo em milheto foi mantido por 67 dias. Ao fim dos tratamentos, as novilhas foram manejadas em grupo único: no pré-parto em pastagem natural, no pós-parto em pastagem de azevém (Lolium multiflorum, Lam) e no segundo período reprodutivo em pastagem natural. Na fase inicial da gestação, o ganho médio diário (GMD), de 0,899 kg, e o ganho de condição corporal (GCC), de 0,34 pontos das PMI, foram superiores ao GMD de 0,377 kg e à perda de $-0,15$ de $\mathrm{CC}$ das PNA. As novilhas PMI tiveram peso vivo pós-parto (PVP) e condição corporal pós-parto (CCP) de $301 \mathrm{~kg}$ e de 2,9 pontos, valores superiores aos das PNA, de $267 \mathrm{~kg}$ e 2,7 pontos, respectivamente. As taxas de parição, distocia, natalidade e desmame não diferiram entre os tratamentos alimentares. As novilhas PMI chegaram ao início do segundo período reprodutivo com peso (31 $\mathrm{kg}$ a mais) e condição corporal $(0,30$ ponto a mais $)$ superiores. A taxa de prenhez e as estimativas de eficiência produtiva ao parto (EPVP) e ao desmame dos bezerros aos 100 dias de idade (EPVD) não foram alteradas pelo tratamento alimentar. A TP média foi de 77\%, a EPVP média de 30,3 e a EPVD de 28,1 kg de bezerro desmamado/ $100 \mathrm{~kg}$ de vaca.

Palavras-chave: condição corporal, desempenho reprodutivo, eficiência produtiva, gado de cria, pastagem natural, sistema "um ano"

\section{Pregnant heifers management at 13/15 months of age in grazing systems}

\begin{abstract}
This experiment was carried out to evaluate the development of 32 primiparous beef heifers Aberdeen Angus and Angus crossbred raised and mating from 13 to the 15 months of age. The experiment had beginning in the pregnancy diagnosis of using ultra-sound technique, realized at 28 days after the ending of the reproductive period. The initial average weight and body condition (BC) was $288 \mathrm{~kg} \mathrm{LW}$ and 3.2 points, respectively. In this occasion, the beef heifers were uniformly distributed by genetic group, LW and conception order in two grazing systems. Grazing systems were: PMI - pregnant beef heifers maintained in the initial pregnancy period on pearl millet pasture (Pennisetum americanum, L.); PNA - pregnant heifers maintained in the initial pregnancy period on natural pasture. Grazed period was 67 days in pearl millet pasture. At end of the treatments the beef heifers were maintained as a unique group: on natural pasture at pre calving period, on annual ryegrass (Lolium multiflorum, Lam) pasture at post calving period and on natural pasture at second reproductive period. In the initial pregnancy phase, the average daily gain (ADG) of $0.899 \mathrm{~kg}$ and body condition gain (BCG), 0.34 points of the PMI heifers were higher then the ADG of $0.377 \mathrm{~kg}$ and $\mathrm{BC}$ lost of -0.15 for PNA heifers. The PMI beef heifers had post calving live weight (PCW) and post calving body condition of $301 \mathrm{~kg}$ and 2.9 points, respectively, higher values than of PNA beef heifers, $267 \mathrm{~kg}$ and 2.7 points. Calving, dystocia, birth and weaning rates were not different between the feeding treatment. The PMI beef heifers were $31 \mathrm{~kg}$ heaviest and with more 0.30 point of $\mathrm{BC}$ at initial second reproductive period. The pregnancy rate (PR) and estimations of calving productive efficiency (CPEE) and weaning productive efficiency at 100 days of age (WPEE) were not different between feeding treatments. Mean PR was 77\%. Mean CPEE was 30.3 and WPEE $28.1 \mathrm{~kg}$ of weaning calf/100 kg of cow.
\end{abstract}

Key Words: body condition, breeding cows, natural pasture, "one year old" system, productive efficiency, reproductive performance 


\section{Introdução}

A baixa taxa de prenhez das vacas primíparas pode inviabilizar o investimento necessário à concepção de novilhas de corte dos 13 aos 15 meses de idade. Para este sistema ser uma opção biologicamente mais eficiente, a produção líquida durante quatro anos de vida reprodutiva da vaca parida aos 24 meses de idade deve exceder à de novilhas prenhes em idades mais elevadas (Pötter et al., 2000).

Independentemente da idade ao parto, a primípara requer especial atenção. O planejamento alimentar desta categoria entre a parição e o final do segundo período reprodutivo está condicionado ao peso e à condição corporal ao parto. O peso ao primeiro parto é o mais importante determinante da prenhez no segundo período reprodutivo (Rovira, 1974), mesmo ocorrendo aumento no peso até o acasalamento.

A vaca de corte ideal é aquela que em um período de 12 meses se torna gestante nas primeiras semanas da estação reprodutiva, pare e desmama um bezerro saudável e repete prenhez no início do período reprodutivo subseqüente. Para isso ocorrer com as fêmeas em reprodução, as vacas devem ser manejadas para parir com condição corporal entre 3,5 e 4,0 (escala 1 a 5) e ser alimentadas para minimizar as perdas de reservas corporais durante o início da lactação (Lobato, 2003).

Vacas paridas aos 24 meses de idade possuem demanda nutricional maior e chegam mais debilitadas ao parto. Com o intuito de evitar baixo peso ao parto, pastos de alta qualidade podem ser utilizados para se obter ganho de peso elevado no período inicial da gestação e aumento significativo na condição corporal.

No propósito de utilização de pastos de alta qualidade deve-se considerar a demanda nutricional da categoria animal e relacioná-la à taxa de ganho de peso desejada e ao período de pastejo necessário para a obtenção dos resultados. Neste contexto, o milheto (Pennisetum americanum, L.) pode ser uma alternativa, em virtude da alta capacidade de produção de forragem de qualidade que possibilita elevados ganhos de peso em período coincidente com a fase inicial de gestação das novilhas.

Com a redução da idade ao primeiro parto, a ocorrência de distocia pode se tornar mais freqüente e influenciar diretamente a eficiência produtiva do rebanho. Um dos fatores para o aumento da distocia é o excesso de ganho de peso da fêmea no terço final de gestação, fase de maior desenvolvimento fetal.

As pastagens naturais na Região Sul do Brasil devem ser utilizadas preferencialmente para as vacas de cria. $\mathrm{O}$ terço final de gestação, na maioria das vezes, coincide com o inverno, quando as pastagens naturais não melhoradas não apresentam acúmulo de forragem significativo e a massa de forragem disponível aos animais é de baixa qualidade, levando as vacas à perda de reservas corporais para manutenção da gestação (Lobato et al., 1998).

A hipótese testada neste trabalho é que, quando proporcionado maior ganho de peso no período inicial de gestação, a novilha primípara gestante a partir dos 13 aos 15 meses de idade pode apresentar melhor desenvolvimento e desempenho reprodutivo.

Objetivou-se avaliar o desenvolvimento e o desempenho reprodutivo de vacas primíparas dos 22 aos 24 meses de idade do início da gestação até o final do segundo período reprodutivo de acordo com o nível alimentar da fase inicial.

\section{Material e Métodos}

O experimento foi realizado em área da Agropecuária Nossa Senhora de Lourdes, município de Tupanciretã, Rio Grande do Sul. O período de avaliação foi de fevereiro de 2004 a março de 2005. A propriedade está localizada na região fisiográfica denominada Planalto Médio, com altitude média de $180 \mathrm{~m}$, latitude $29^{\circ} 03^{\prime}$ Sul e longitude $53^{\circ} 48^{\prime}$ Oeste.

O relevo da região é ondulado, com coxilhas de solos profundos, naturalmente ácidos e de textura superficial média. O solo é classificado como Latossolo Vermelho Distroférrico típico (EMBRAPA, 1999) e o clima da região é subtropical conforme classificação de Köppen (Moreno, 1961).

Foram utilizadas 32 novilhas gestantes contemporâneas Aberdeen Angus e mestiças Angus provenientes de dois criatórios da região, Cabanha Santa Cecília (Santiago, RS) e Cabanha Capitão Rodrigo (Jari, RS), recriadas e acasaladas dos 13 aos 15 meses de idade na própria Agropecuária Nossa Senhora de Lourdes.

O experimento teve início no diagnóstico de gestação pela técnica de ultra-sonografia, transdutor transretal linear de $5 \mathrm{MHz}$ de freqüência, realizado em 27/2/2004, 28 dias após o término do período reprodutivo. O peso vivo (PV) inicial médio foi de $288 \mathrm{~kg}$ e a condição corporal (CC) inicial média de 3,2 pontos. Nesta ocasião, as novilhas foram distribuídas uniformemente por grupo genético, peso vivo e ordem de concepção em dois tratamentos alimentares:

PMI - novilhas mantidas na fase inicial de gestação em pastagem de milheto;

PNA - novilhas mantidas na fase inicial de gestação em pastagem natural. 
O período de pastejo em milheto foi de 67 dias, de 27/2 a 5/5/2004. A área da pastagem de milheto foi de 32 ha e a da pastagem natural de 45 ha. Após o término do ciclo produtivo na pastagem de milheto, os animais foram manejados em grupo único em pastagem natural até o parto. Após o parto, foram transferidos para uma área (30 ha) de azevém (Lolium multiflorum, Lam) até o início do segundo período reprodutivo.

O segundo período reprodutivo foi em pastagem natural em uma área de 45 ha e ocorreu de 16/11/2004 a 14/2/2005. Foram utilizados dois touros Red Angus de três anos de idade submetidos a exame andrológico prévio.

O método de pastejo foi o contínuo com lotação variável. Empregou-se a técnica do uso de animais reguladores (Mott \& Lucas, 1952) para o ajuste da carga animal (CA) às massas de forragem (MF) pretendidas. Procurou-se manter a MF entre 1.500 e $2.000 \mathrm{~kg} / \mathrm{ha} \mathrm{MS}$ em todas as pastagens. Em cada sistema de pastejo, foram utilizados 16 animais-teste e um número variável de reguladores, conforme a necessidade de ajuste de CA.

$\mathrm{O}$ ajuste de $\mathrm{CA}$ e as medidas de MF, taxa de acúmulo de forragem (TAD) e oferta de forragem (OF) foram realizados em intervalos de aproximadamente 28 dias. A MF foi determinada pela técnica de dupla amostragem (Wilm et al., 1944). Para determinação da TAD, foram alocadas cinco gaiolas de exclusão ao pastejo por potreiro, utilizando-se metodologia descrita por Klingmann et al. (1943). A oferta de forragem (OF) foi calculada dividindo-se a MF por 28 dias somada à TAD. O valor obtido foi multiplicado por 100 e dividido pela CA.

A determinação do valor nutritivo da forragem foi realizada em amostras colhidas por meio de simulação de pastejo (Gibb \& Treacher, 1976). Avaliaram-se os teores de proteína bruta $(\mathrm{PB})$ e fibra detergente neutro (FDN), técnicas descritas pela AOAC (1984).

As pesagens foram realizadas após jejum de 6 horas. $\mathrm{Na}$ fase inicial de gestação, as pesagens foram feitas no início do pastejo (27/2/2004), no período intermediário (3/4/2004) e ao final da utilização da pastagem de milheto $(5 / 5 / 2004)$. Desde então, em pastagem natural pré-parto e pastagem de azevém pós-parto, todos os animais foram pesados nas seguintes datas: $8 / 6 / 2004,17 / 7 / 2004,21 / 8 / 2004$, $3 / 10 / 2004$ e $31 / 10 / 2004$. Independentemente das demais pesagens, as vacas foram pesadas até 12 horas pós-parto e os bezerros também foram pesados e identificados com brincos de plástico.

Em cada pesagem, exceto na pesagem ao parto, avaliou-se o escore de condição corporal (Lowman et al., 1973) com valores de 1 a 5 , em que $1=$ muito magro e $5=$ muito gordo.
O escore de condição corporal ao parto foi calculado a partir do ganho de condição corporal do final do pastejo em milheto até a última avaliação pré-parto. O valor obtido foi ajustado para o número de dias até o parto e depois somado à condição corporal ao final do uso da pastagem de milheto, metodologia adaptada de Hight (1966).

No segundo período reprodutivo, as pesagens foram realizadas ao início (16/11/2004), em períodos intermediários (13/12/2004 e 16/01/2005) e ao final (14/02/2005) dos 90 dias do período reprodutivo.

Como estratégia para potencializar o desempenho reprodutivo das primíparas, os bezerros foram desmamados precocemente em dois grupos: o primeiro de 24 bezerros com 100 dias de idade e $79 \mathrm{~kg}$, em 13/12/2004; e o segundo, de quatro bezerros com 98 dias de idade e $59 \mathrm{~kg}$, em 16/1/2005.

O controle de endoparasitos foi realizado por meio de dosificações no início do período de pastejo e, posteriormente, a cada quatro pesagens. O ganho de peso médio diário (GMD) foi obtido pela diferença entre peso final e inicial dos animais-teste, em cada período experimental, dividido pelo número de dias do período.

As variações diárias médias de peso (VDP) na fase préparto foram calculadas como a diferença entre o peso dos animais-teste na última pesagem antes do parto e a realizada ao final do pastejo em milheto. $\mathrm{O}$ valor obtido foi dividido pelo número de dias entre as pesagens, conforme Hight (1966). Na fase pós-parto, as VDP das vacas foram calculadas pela diferença entre o peso no início do segundo período reprodutivo (15/11/2004) e o peso ao parto. O valor obtido foi dividido pelo número de dias entre as respectivas pesagens.

Para as variações de condição corporal (VCC), foram adaptados os critérios adotados para a VDP. No pré-parto, foi calculada a diferença entre a última condição corporal observada antes do parto e a condição corporal ao final da pastagem de milheto. No pós-parto, calculou-se a diferença entre a CC ao início do segundo período reprodutivo e a $\mathrm{CC}$ ao parto.

A taxa de parição (TPA) correspondeu ao percentual de vacas paridas e a taxa de natalidade (TNA), à porcentagem de bezerros vivos até 24 horas pós-parto. A taxa de desmame (TDE) correspondeu à porcentagem de bezerros desmamados aos 100 dias. Todas essas taxas foram calculadas em relação ao total de vacas prenhes ao início do experimento. A taxa de distocia (TDI) incluiu a porcentagem de vacas com dificuldade de parto em relação ao número de vacas paridas.

A partir do parto, somente as vacas com cria ao pé continuaram como repetições dos tratamentos. As vacas que perderam bezerro seguiram como animais reguladores 
no ajuste da carga animal. A taxa de prenhez (TP) representou a porcentagem de vacas com cria ao pé prenhes no segundo período reprodutivo.

O diagnóstico de gestação do segundo período reprodutivo foi realizado 23 dias após o seu término $(8 / 3 / 2005)$ utilizando-se a técnica de ultra-sonografia. As vacas foram classificadas pelo desenvolvimento do embrião ou feto quanto ao período da concepção em vacas prenhes no terço inicial, intermediário ou final da estação de monta, respectivamente.

As estimativas das medidas de eficiência produtiva foram obtidas a partir das características quantificadas, conforme metodologia descrita por Ribeiro et al. (2001). A primeira estimativa de eficiência foi considerada como a quantidade $(\mathrm{kg})$ de bezerros desmamados para cada $100 \mathrm{~kg}$ de vacas paridas: $\mathrm{EPVP}=(\mathrm{P} 100 / \mathrm{PVP}) * 100$, em que $\mathrm{EPVP}=$ eficiência produtiva ao parto; $\mathrm{P} 100=$ peso do bezerro ajustado aos 100 dias de idade; e PVP = peso da vaca ao parto. A segunda estimativa foi a eficiência produtiva ao desmame (EPVD), na qual o PVP foi substituído pelo peso da vaca ao desmame do bezerro (PVD): EPVD $=(P 100 / P V D) * 100$.

$\mathrm{O}$ delineamento experimental foi o inteiramente casualizado com parcelas subdivididas no tempo. Foram tomados os animais-teste como repetições. Os dados coletados foram submetidos à análise de variância e ao teste F utilizando-se o seguinte modelo matemático:

$$
\mathrm{Y}_{\mathrm{ijkl}}=\mu+\mathrm{T}_{\mathrm{i}}+\mathrm{A}_{\mathrm{j}}(\mathrm{T})_{\mathrm{i}}+\mathrm{P}_{\mathrm{k}}+\left(\mathrm{T}^{*} \mathrm{P}\right)_{\mathrm{ik}}+\varepsilon_{\mathrm{ijk}}
$$

em que: $\mathrm{Y}_{\mathrm{ijk}}=$ variáveis dependentes; $\mu=$ média de todas as observações; $T_{i}=$ efeito do i-ésimo tratamento alimentar; $A_{j}(T)_{i}=$ efeito do j-ésimo animal no i-ésimo tratamento alimentar (erro A); $\mathrm{P}_{\mathrm{k}}=$ efeito do k-ésimo período; $(\mathrm{T} * \mathrm{P})_{\mathrm{ik}}=$ efeito de interação entre o i-ésimo tratamento alimentar e o k-ésimo período; $\varepsilon_{\mathrm{ijk}}=$ erro residual (erro B).

Quando detectada diferença entre os sistemas de pastejo, realizou-se o teste Tukey para comparação de médias. As análises foram feitas com auxílio do procedimento "general linear model" (GLM). Os dados referentes à taxa de prenhez e ao período da concepção foram analisados pelo método do Qui-quadrado utilizando-se o programa estatístico SAS, versão 6.08 (SAS, 1997) e adotando-se 5\% como nível de significância máximo das análises.

\section{Resultados e Discussão}

Na fase inicial de gestação, a TAD (32 kg/ha), os teores de PB (1 4,2\%) e de FDN (66\%) da pastagem de milheto mantiveram-se abaixo do potencial desta espécie, provavelmente em virtude do seu avançado estágio vegetativo (Tabela 1). À medida que o ciclo de produção da pastagem de milheto avança, verificam-se alteração linear decrescente na relação lâmina foliar/colmo e redução na qualidade do material ingerido por animais em pastejo (Santos et al., 2005). A baixa densidade de forragem e a elevada dispersão espacial de folhas desta pastagem em final de ciclo podem dificultar o processo de ingestão pelos animais, em razão do aumento do tempo necessário para a formação do bocado (Carvalho et al., 2001).

A pastagem natural se localizava em áreas marginais aos solos de coxilhas, formadas por brejos parcialmente drenados e encostas. A massa de forragem média de $2.116 \mathrm{~kg} / \mathrm{ha}$ de MS não permitiu a estrutura da pastagem se tornar mais grosseira, mesmo com oferta de forragem de $49 \mathrm{~kg}$ MS/100 kg PV, provavelmente em virtude da baixa TAD, $10 \mathrm{~kg} / \mathrm{ha}$ de MS, além do período restrito a 66 dias de pastejo. Em um sistema real de produção, o uso de ofertas de forragem diferentes ao longo das estações do ano é comum, pois a carga animal não acompanha a curva de disponibilidade de forragem (Nabinger, 2006).

O desenvolvimento durante a fase inicial de gestação (Tabela 2) diferiu entre as novilhas gestantes mantidas em pastagem de milheto (PMI) e aquelas mantidas em pastagem natural (PNA). O ganho médio diário, de $0,899 \mathrm{~kg}$, e o GCC, de 0,34 ponto, das PMI foram superiores aos das novilhas PNA: GMD de 0,377 kg e perda de CC de -0,15.

Tabela 1 - Características produtivas de pastagens utilizadas por vacas primíparas no período da gestação ao segundo período reprodutivo

\begin{tabular}{|c|c|c|c|c|c|}
\hline \multirow{2}{*}{$\begin{array}{l}\text { Item } \\
\text { Pastagem }\end{array}$} & \multicolumn{2}{|c|}{$\begin{array}{l}\text { Fase inicial } \\
\text { gestação }\end{array}$} & \multirow{2}{*}{$\begin{array}{l}\text { Pré-parto } \\
-1 \text { Natural }\end{array}$} & \multirow{2}{*}{$\begin{array}{c}\text { Pós-parto } \\
\text { Azevém }\end{array}$} & \multirow{2}{*}{$\begin{array}{l}\text { Acasal } \\
\text { Natura }\end{array}$} \\
\hline & Milheto & Natural & & & \\
\hline MF (kg/ha MS) & 1.766 & 2.116 & 1.761 & 1.330 & 1.586 \\
\hline TAD (kg/ha MS) & 32 & 10 & 3 & 65 & 22 \\
\hline $\begin{array}{l}\text { OF (kgMS/ } \\
100 \mathrm{kgPC})\end{array}$ & 10 & 49 & 36 & 21 & 24 \\
\hline CA (kg/ha PC) & 967 & 233 & 235 & 540 & 332 \\
\hline PB (\%) & 14,2 & 8,4 & 9,1 & 16,6 & 7,9 \\
\hline FDN $(\%)$ & 66 & 76 & 73 & 57 & 72 \\
\hline
\end{tabular}

1 Período de 28/2/2004 a 5/5/2004; ${ }^{2}$ Período de 6/5/2004 a 15/11/2004

${ }^{3}$ Acasalamento: Período de 16/11/2004 a 14/2/2005.

Tabela 2 - Ganho médio diário (GMD), ganho de condição corporal (GCC), peso vivo (PVF) e condição corporal (CCF) finais de novilhas dos 13 aos 15 meses de idade em pastagem natural ou milheto na fase inicial da gestação

\begin{tabular}{lcccc}
\hline Pastagem & GMD, kg & GCC, 1-5 & PVF, kg & CCF, 1-5 \\
\hline Natural (PNA) & $0,377 \mathrm{~b}$ & $-0,15 \mathrm{~b}$ & $313 \mathrm{~b}$ & $3,1 \mathrm{~b}$ \\
Milheto (PMI) & $0,899 \mathrm{a}$ & $0,34 \mathrm{a}$ & $346 \mathrm{a}$ & $3,6 \mathrm{a}$ \\
\hline CV (\%) & 21,2 & 236,7 & 8,5 & 9,5 \\
\hline
\end{tabular}

$a$, b na mesma coluna, diferem entre si $(P<0,01)$; Período: 28/2/2004 a 5/5/2004. 
Os ganhos de peso obtidos estão de acordo com o potencial produtivo destas espécies forrageiras. Rocha et al. (2004) observaram GMD de 0,814 kg com novilhas de mesma idade, porém em recria. Na mesma ocasião, verificaram em novilhas em pastagem natural GMD de $0,359 \mathrm{~kg}$.

Moraes \& Maraschin (1988) relataram GMD em torno de $1,0 \mathrm{~kg}$ para novilhos em pastagem de milheto. Moojen \& Maraschin (2002) demonstraram, na Depressão Central do Rio Grande do Sul, potencial de ganho de peso de novilhos em pastagem natural de $0,500 \mathrm{~kg} /$ dia durante a estação de crescimento. Com novilhas de sobreano, Pereira Netto \& Lobato (1998) relataram GMD de 0,246 kg em pastagem natural.

Os aumentos obtidos na fase inicial de gestação possibilitaram às novilhas do PMI ao final dos 66 dias de pastejo maior peso vivo (PVF), $346 \mathrm{~kg}$, e condição corporal (CCF) mais elevada, 3,6 pontos. O desempenho inferior das PNA permitiu PVF de $313 \mathrm{~kg}$ e, praticamente, manter a CC inicial de 3,2, considerando a CCF de 3,1 pontos.

O melhor desenvolvimento das PMI ao início do período de outono/inverno, diferença de $33 \mathrm{~kg}$ de PV e 0,5 ponto de $\mathrm{CC}$, possibilitou maior peso vivo (PVP) e condição corporal (CCP) pós-parto (Tabela 3). As primíparas PMI tiveram PVP de $301 \mathrm{~kg}$ e CCP de 2,9 pontos, valores superiores aos das PNA de $267 \mathrm{~kg}$ e 2,7 pontos, respectivamente. A diferença pós-parto foi $34 \mathrm{~kg}$ de $\mathrm{PV}$ e semelhante à do início do outono/inverno. Na CCP houve, no entanto, redução na diferença para 0,2 ponto.

Nicoll (1979) citou superioridade de 1,3 ponto de condição corporal pós-parto para vacas com maiores níveis nutricionais no pré-parto. A condição corporal ao parto é provavelmente o fator mais importante a afetar o desempenho reprodutivo de vacas de corte (Morrison et al., 1999) e está correlacionada à condição corporal ao início do acasalamento subseqüente (Sampedro et al., 2000). Pötter \& Lobato (2004) observaram aumento de 0,57 ponto de

Tabela 3 - Peso vivo (PVP) e condição corporal (CCP) pós-parto e peso ao nascer de bezerros (PNB) de vacas primíparas aos 22/24 meses de idade mantidas em pastagem natural ou de milheto na fase inicial da gestação

\begin{tabular}{lccc}
\hline Início da gestação & $\begin{array}{c}\text { PVP } \\
\mathrm{kg}\end{array}$ & $\begin{array}{c}\mathrm{CCP} \\
1-5\end{array}$ & $\begin{array}{c}\text { PNB } \\
\mathrm{kg}\end{array}$ \\
\hline Natural (PNA) & $267 \mathrm{~b}$ & $2,7 \mathrm{~B}$ & 25 \\
Milheto (PMI) & $301 \mathrm{a}$ & $2,9 \mathrm{~A}$ & 25 \\
Média & & & 25 \\
\hline CV (\%) & 12,2 & 11,2 & 18,8 \\
\hline
\end{tabular}

a, b na mesma coluna diferem entre si $(P=0,01) ; A, B$ na mesma coluna diferem entre si $(P=0,05)$. condição corporal ao início do acasalamento para cada ponto a mais na condição corporal ao parto.

No período de outono/inverno pré-parto, as primíparas praticamente mantiveram o peso, independentemente do sistema de pastejo no período inicial de gestação. A variação diária de peso vivo (VDP) foi de -0,008 $\mathrm{kg}$ (Tabela 4).

A perda de CC até o parto das PMI foi maior que das PNA. A variação da condição corporal (VCC) das PMI foi de $-0,61$, perda superior aos $-0,34$ ponto das PNA durante os 119 dias de pastagem natural pré-parto. Moraes \& Lobato (1993), ao analisarem vacas Polled Hereford primíparas aos 40/42 meses de idade nos períodos pré e pós-parto, registraram perda de peso de $48 \mathrm{~kg}$ e 0,37 ponto de $\mathrm{CC}$ em pastagem natural.

No pós-parto, em pastagem de azevém, as primíparas tiveram VDP de $0,258 \mathrm{~kg}$ e mantiveram a CC, independentemente do sistema de pastejo adotado no período inicial de gestação. A VCC foi de $-0,05$ ponto durante os 74 dias entre o parto e o início do segundo período reprodutivo.

Vacas primíparas mantidas em pastagens naturais com introdução de espécies hiberno-primaveris apresentam melhores índices reprodutivos na estação subseqüente (Lobato et al., 1998). De acordo com Rice (1991), a grande demanda por nutrientes para a lactação e os efeitos inibitórios do ato da mamada pelo bezerro sobre a secreção de GnRH e de gonadotrofinas são mais expressivos em vacas com baixa CC. Portanto, pastagens de alta qualidade no pós-parto são fundamentais para o desenvolvimento de vacas primíparas aos 22/24 meses de idade.

As taxas de parição, distocia, natalidade e desmame não foram alteradas pelo maior nível nutricional na fase inicial de gestação (Tabela 5). A taxa de distocia média de $19,7 \%$ pode ser considerada baixa para fêmeas primíparas aos $22 / 24$ meses de idade.

Tabela 4 - Variação diária de peso vivo (VDP), variação da condição corporal (VCC) e dias pré e pós-parto de vacas primíparas aos 22/24 meses de idade mantidas em pastagem natural ou milheto na fase inicial da gestação

\begin{tabular}{|c|c|c|c|c|c|c|}
\hline \multirow[t]{2}{*}{ Início da gestação } & \multicolumn{3}{|c|}{ Pré-parto } & \multicolumn{3}{|c|}{ Pós-parto } \\
\hline & $\begin{array}{l}\text { VDP } \\
(\mathrm{kg})\end{array}$ & $\begin{array}{c}\text { VCC } \\
(1-5)\end{array}$ & Dias & $\begin{array}{l}\text { VDP } \\
(\mathrm{kg})\end{array}$ & $\begin{array}{c}\text { VCC } \\
(1-5)\end{array}$ & Dias \\
\hline Natural (PNA) & 0,019 & $-0,34 \mathrm{~B}$ & 119 & 0,287 & $-0,01$ & 73 \\
\hline Milheto (PMI) & $-0,036$ & $-0,61 \mathrm{~A}$ & 117 & 0,229 & $-0,08$ & 75 \\
\hline Média & $-0,008$ & & 118 & 0,258 & $-0,05$ & 74 \\
\hline $\mathrm{CV}(\%)$ & 15,7 & 66,8 & 16,5 & 22,4 & 32,1 & 26,9 \\
\hline
\end{tabular}

$A$, B na mesma coluna, diferem entre si $(P<0,05)$.

Pré-parto: pastagem natural; Pós-parto: pastagem de azevém; Período: $6 / 5 / 2004$ a $15 / 11 / 2004$. 
Tabela 5 - Taxas de parição, distocia, natalidade e desmame (\%) de vacas primíparas aos 22/24 meses de idade mantidas em pastagem natural ou de milheto na fase inicial da gestação

\begin{tabular}{lcccc}
\hline Início da gestação & Parição & Distocia & Natalidade & Desmame \\
\hline Natural (PNA) & 93,8 & 26,7 & 75,0 & 75,0 \\
Milheto (PMI) & 100,0 & 12,7 & 93,8 & 93,8 \\
\hline Média & 96,9 & 19,7 & 84,4 & 84,4 \\
\hline
\end{tabular}

$\mathrm{P}>0,05$.

Os fatores determinantes para a baixa porcentagem de distocia foram o manejo alimentar pré-parto em pastagem natural e a utilização de touros de raças de tamanho moderado e de linhagens de diferença esperada na progênie (DEP) negativa ou próxima de zero para peso ao nascer. $\mathrm{O}$ peso ao nascer médio dos bezerros foi de $25 \mathrm{~kg}$ (Tabela 3) com coeficiente de variação de $18,8 \%$.

De acordo com Reynolds et al. (1991), baixas porcentagens de distocia em primíparas nesta idade ocorrem quando utilizados touros da raça Tarentaise (23,3\%) e Angus (28,9\%) e valores mais altos são verificados com a utilização de touros Pinzgauer $(54,4 \%)$ e Simental $(60,8 \%)$. Segundo Bellows \& Short (1994), com a redução da idade ao primeiro parto, a ocorrência de distocia se torna mais freqüente e influencia diretamente a eficiência produtiva do rebanho por meio da perda de bezerros. Neste trabalho, a diferença entre as taxas de parição e de natalidade foi conseqüência de uma taxa de mortalidade de bezerros ao parto de $12,5 \%$. A taxa de desmame foi igual à de natalidade, evidenciando a importância do manejo alimentar utilizado no pós-parto igual para todos os animais.

O peso vivo (PVI) e a condição corporal (CCI) das PMI, de $322 \mathrm{~kg} \mathrm{e} 3,0$ pontos no início do segundo período reprodutivo, foram superiores aos observados nas PNA de 291 e 2,7 pontos, respectivamente (Tabela 6). As PMI foram $31 \mathrm{~kg}$ mais pesadas e sua condição corporal foi 0,30 ponto melhor - pesos baixos e limitantes de altas taxas de prenhez. Ribeiro \& Lobato (1988) e Gottschall \& Lobato (1996), trabalhando com primíparas, verificaram que os baixos PVI e CCI foram responsáveis pelos baixos índices de prenhez em primíparas.

Vacas primíparas com melhor condição corporal ao parto apresentam maior taxa de prenhez no período reprodutivo subseqüente. Barcellos et al. (1997) verificaram aumentos de 47,3 e $80,5 \%$ na taxa de prenhez de novilhas com condições corporais 3 e 5 , respectivamente em comparação àquelas de condição corporal 1 (escala de 1 a 5).

Os PVI de $322 \mathrm{~kg}$ das PMI e $291 \mathrm{~kg}$ das PNA representaram, respectivamente, 68 e $62 \%$ do peso adulto das fêmeas do rebanho. O peso adulto das fêmeas dos rebanhos em estudo era de $470 \mathrm{~kg}$. O peso vivo mínimo necessário para
Tabela 6 - Peso vivo (PVI) e condição corporal (CCI) ao início do segundo período reprodutivo, taxa de prenhez e ordem de concepção de vacas primíparas mantidas em pastagem natural ou de milheto

\begin{tabular}{lcccccc}
\hline $\begin{array}{l}\text { Início da } \\
\text { gestação }\end{array}$ & $\begin{array}{c}\text { PVI } \\
(\mathrm{kg})\end{array}$ & $\begin{array}{c}\text { CCI } \\
(1-5)\end{array}$ & $\begin{array}{c}\text { T P } \\
(\%)\end{array}$ & \multicolumn{3}{c}{$\begin{array}{c}\text { Período de } \\
\text { concepção }\end{array}$} \\
\cline { 4 - 7 } & & & & Inicial & Interm. Final \\
\hline Natural (PNA) & $291 \mathrm{~B}$ & $2,7 \mathrm{~B}$ & 67 & 0 & 50 & 50 \\
Milheto (PMI) & $322 \mathrm{~A}$ & $3,0 \mathrm{~A}$ & 87 & 15 & 39 & 46 \\
Média & & & 77 & 8 & 44 & 48 \\
\hline CV (\%) & 10,9 & 10,2 & & & & \\
\hline
\end{tabular}

$A, B$ na mesma coluna diferem entre si $(P<0,05)$. Período: 16/11/2004-14/2/2005.

a primípara se tornar gestante ao início do segundo período reprodutivo, segundo Rovira (1974), é de $85 \%$ do seu peso à idade adulta. Os percentuais atingidos neste estudo foram bem inferiores. Ao início do trabalho, quando novilhas estavam em início de gestação, o percentual em relação ao peso adulto foi de $61 \%(287 \mathrm{~kg})$. Portanto, as PMI tiveram desenvolvimento de apenas $7 \%$ e as PNA de $1 \%$ do peso à idade adulta entre o início da primeira gestação (27/2/2004) e o início do segundo período reprodutivo (16/11/2004) em um total de 259 dias.

Pesos tão baixos ao início do período reprodutivo e de vacas primíparas justificam o desmame antecipado dos bezerros para obtenção de prenhez mais elevada e necessária economicamente. Em sistemas de ciclo completo, Beretta et al. (2001) afirmaram que é imprescindível a obtenção de índices de natalidade próximos de $78 \%$ no rebanho de cria adulto. Conforme revisão de Lobato (1996), várias pesquisas comprovaram aumento de $40 \%$ para $70 \%$ de prenhez em vacas com bezerros submetidos a desmame precoce.

A fêmea bovina apresenta crescimento ativo até os 4 anos de idade (Freetly, 1999). Quando exposta à reprodução dos 13 aos 15 meses de idade apresenta maiores exigências nutricionais, pois, além de estarem em fase de crescimento, precisam de nutrientes para a reprodução (Scaglia, 1997).

Em trabalho conduzido com animais Nelore durante quatro anos consecutivos, Vieira et al. (2005) determinaram em vacas e novilhas acasaladas aos 24 meses de idade efeitos significativos da ordem de parto (OP) e da condição corporal (CC) sobre as taxas de prenhez. Nas primíparas (OP1) com CC 2,0 , os autores observaram TP de $52,7 \%$, mas naquelas com CC de 3,5 a TP foi de $82,5 \%$.

Quanto pior a condição corporal da vaca, mais cedo deve ser realizado o desmame visando à melhoria das condições fisiológicas da fêmea e a probabilidade de ela conceber (Rovira, 1996). Neste trabalho, o desmame aos 100 dias de idade foi usado como recurso para potencializar 
o desempenho reprodutivo das primíparas e permitir que continuassem em desenvolvimento para atingir o peso adulto. Com a estabilização da produção de leite, as exigências nutricionais diminuem e a vaca pode utilizar os nutrientes ingeridos para outras funções. Além disso, a presença do bezerro constitui um inibidor das funções hormonais relacionadas ao retorno da atividade reprodutiva (Montiel \& Ahuja, 2005).

As taxas de prenhez foram de 67 e $87 \%$ para PNA e PMI, respectivamente (média de 77\%). O desmame dos bezerros não permitiu antecipar a concepção dentro do período reprodutivo, uma vez que $48 \%$ das primíparas ficaram prenhes no seu terço final. Simeone \& Lobato (1996) verificaram efeito significativo do controle da amamentação sobre o ganho de peso e a taxa de prenhez de vacas primíparas no período entre a metade e o fim do acasalamento. De acordo com esses autores, vacas do desmame aos 90 dias apresentaram ganhos de peso e taxa de prenhez superiores às do aleitamento interrompido e da idade convencional (180 dias).

Pio de Almeida et al. (2002) observaram efeitos do desmame aos 90 dias de idade na taxa reprodutiva da temporada em que foi realizado e na do ano subseqüente com bezerro ao pé. Neste trabalho, a taxa de prenhez foi de $51,4 \%$, enquanto, para as vacas mantidas com seus bezerros no ano anterior, a taxa foi de apenas $20 \%$. De acordo com esses autores, o desmame permitiu aumento de peso e de condição corporal.

O maior peso das vacas ao desmame ajustado para 100 dias de idade (PVD) entre as PMI (23 kg a mais em relação às PNA) não promoveu aumento dessa mesma variável medida nos bezerros (PVB), de $86 \mathrm{~kg}$ (Tabela 7). Considerando peso médio dos bezerros ao nascer de $25 \mathrm{~kg}$ (Tabela 3), o GMD foi de $0,610 \mathrm{~kg}$ do nascimento aos 100

Tabela 7 - Peso da vaca ao desmame (PVD), peso do bezerro ajustado para 100 dias de idade (PVB) e médias estimadas para medidas de eficiência produtiva $(\mathrm{kg}$ de bezerro desmamado/100 $\mathrm{kg}$ de vaca) ao parto (EPVP) e ao desmame (EPVD) de vacas primíparas mantidas na fase inicial da gestação em pastagem natural ou de milheto

\begin{tabular}{lcccc}
\hline Início da gestação & PVD & PVB & EPVP & EPVD \\
\hline Natural (PNA) & 296B & 85 & 31,5 & 29,0 \\
Milheto (PMI) & 319A & 87 & 29,3 & 27,3 \\
Média & & 86 & 30,3 & 28,1 \\
\hline CV (\%) & 11,8 & 20,6 & 16,1 & 18,4 \\
\hline
\end{tabular}

$A, B$ na mesma coluna, diferem entre si $(P<0,05)$.

$E P V P=(P 100 / P V P) * 100$

$E P V D=(P 100 / P V D) * 100$. dias de idade. O desenvolvimento dos bezerros durante o período de amamentação pode ser considerado satisfatório em se tratando de primíparas. Em trabalho de Restle et al. (2004), bezerros filhos de vacas multíparas mantidas em pastagem de aveia e azevém no pós-parto apresentaram GMD de $0,717 \mathrm{~kg}$ do nascimento aos 98 dias de idade. Em pastagem natural, os autores verificaram GMD dos bezerros de $0,517 \mathrm{~kg}$ no mesmo período.

A produção de leite da vaca na fase inicial de lactação é determinante sobre o ganho de peso do bezerro (Cerdótes et al., 2004). Avaliando a produção de leite e sua correlação com o ganho de peso dos bezerros, Gleddie \& Berg (1968) verificaram que $68,2 \%$ do GMD dos bezerros é relacionado à amamentação no segundo mês de lactação e apenas de $3,7 \%$ no quarto mês.

A EPVP e a EPVD não foram alteradas pelo sistema de pastejo na fase inicial de gestação. A EPVP média foi de $30,3 \mathrm{~kg}$ e a EPVD de $28,1 \mathrm{~kg}$ de bezerro desmamado $/ 100 \mathrm{~kg}$ de vaca. As respostas obtidas comprovaram bom potencial produtivo para primíparas aos 22/24 meses de idade, considerando que o peso de desmame foi ajustado para 100 dias de idade.

Vacas mais leves e/ou com bezerros de bom desenvolvimento apresentam miaor produtividade (Euclides Filho et al., 1995; Ribeiro et al., 2001). Em trabalho realizado por Ribeiro et al. (2001), vacas Aberdeen Angus primíparas aos 48 meses de idade apresentaram EPVP de 42,9 kg e EPVD de $40,1 \mathrm{~kg}$ de bezerro desmamado $/ 100 \mathrm{~kg}$ de vaca, com o peso do bezerro ajustado para os 205 dias de idade.

De acordo com Morris (1984), primíparas parindo aos 24 meses de idade são aproximadamente $9 \%$ mais eficientes biologicamente que aquelas que parem um ano mais tarde. Nuñez-Dominguez et al. (1991) concluíram que não é econômico manter no rebanho fêmeas que passam um ano sem produzir ou parem somente aos 3 anos de idade. Portanto, a TP de $77 \%$ no segundo período reprodutivo (Tabela 6) assegura a eficiência biológica das primíparas aos 22/24 meses de idade.

A presença de maior número de vacas jovens no rebanho de cria diminuiu o peso médio do mesmo e aumentou a eficiência biológica quando mantidos altos índices de prenhez. A viabilidade econômica desse sistema de produção, no entanto, deve ser analisada considerando as particularidades de cada sistema de produção, principalmente quanto aos recursos forrageiros disponíveis e ao nível de evolução genética de cada rebanho. A resposta bioeconômica às mudanças na idade ao primeiro serviço é condicionada pela taxa de natalidade do rebanho adulto e diminui de forma quadrática quando esta taxa de natalidade diminui (Beretta et al., 2001). 


\section{Conclusões}

Novilhas com ganhos de peso próximos a $0,900 \mathrm{~kg} / \mathrm{dia}$ na fase inicial de gestação mantêm maior peso e condição corporal do parto até o início do segundo período reprodutivo. Em vacas primíparas, ganhos de peso durante a fase inicial de gestação próximos a $0,900 \mathrm{~kg} / \mathrm{dia}$ não alteram o desempenho reprodutivo e a eficiência biológica.

\section{Literatura Citada}

ASSOCIATION OF OFFICIAL ANALYTICAL CHEMISTS - AOAC. Official methods of analysis. 14.ed. Washington, D.C.: 1984. $1141 \mathrm{p}$.

BARCELLOS, J.O.J.; LOBATO, J.F.P.; FRIES, L.A. Desempenho reprodutivo de vacas primíparas Hereford e mestiças NeloreHereford com estação de parição e monta no outono/inverno ou primavera/verão. 1. Taxa de prenhez. Revista Brasileira de Zootecnia, v.26, n.5, p.976-985, 1997.

BELLOWS, R.A.; SHORT, R.E. Reproductive losses in beef industry. In: FIELDS, M.J., SAND, R.S. (Eds.) Factors affecting calf crop. Gainesville: CRC Press, 1994. p.109-133.

BERETTA, V.; LOBATO, J.F.P.; MiElitZ NETTO, C.G.A. Produtividade e eficiência biológica de sistemas pecuários diferindo na idade de das bezerras ao primeiro parto e na taxa de natalidade do rebanho no Rio Grande do Sul. Revista Brasileira de Zootecnia, v.30, n.4, p.1278-1286, 2001.

CARVALHO, P.C.F.; MARÇAL, G.K.; RIBEIRO FILHO, H.M.N. et al. Pastagens altas podem limitar o consumo dos animais. In: REUNIÃO ANUAL DA SOCIEDADE BRASILEIRA DE ZooteCNiA, 38., 2001, Piracicaba. Anais... Piracicaba: Sociedade Brasileira de Zootecnia, 2001. (CD-ROM).

CERDótes, L.; RESTle, J.; ALVES FILHO, D.C. et al. Desempenho de bezerros de corte filhos de vacas submetidas a diferentes manejos alimentares, desmamados aos 42 ou 63 dias de idade. Revista Brasileira de Zootecnia, v.33, n.3, p.597609, 2004.

EMPRESA BRASILEIRA DE PESQUISA E AGROPECUÁRIA EMBRAPA. Centro Nacional de Pesquisa de Solos. Sistema brasileiro de classificação de solos. Brasília; Rio de Janeiro, 1999. $412 \mathrm{p}$.

EUCLIDES FILHO, K.; FIGUEIREDO, G.R.; EUCLIDES, V.P.B. Eficiência de produção de vacas de corte com diferentes potenciais para produção de leite. Pesquisa Agropecuária Brasileira, v.30, n.7, p.1003-1007, 1995.

FREETLY, H.C. The replacement heifer and the primiparous cow. In: REUNIÃO ANUAL SOCIEDADE BRASILEIRA DE ZOOTECNIA, 36., 1999, Porto Alegre. Anais... Porto Alegre: Sociedade Brasileira de Zootecnia, 1999. p.241-249.

GIBB, M.J.; TREACHER, T.T. The effect of herbage allowance on herbage intake and performance of lambs grazing perennial ryegrass and red clover swards. Journal of Agricultural Science, v.86, p.355-365, 1976.

GLEDDIE, V.M.; BERG, R.T. Milk production in range beef cows and it's relationship to calf gains. Canadian Journal of Animal Science, v.48, p.323-333, 1968.

GOTTSCHALL, C.S.; LOBATO, J.F.P. Comportamento reprodutivo de vacas de corte primíparas submetidas a três lotações em campo nativo. Revista Brasileira de Zootecnia, v.25, n.1, p. $46-57,1996$.

HIGHT, G.K. The effects of the under nutrition in late pregnancy on beef cattle production. New Zealand Agricultural Research, v.9, n.3, p.479-490, 1966.
KLINGLMANN, D.L.; MILES, S.R.; MOTT, G.O. The cage method for determining consumption and yield of pasture herbage. Journal of Society of Agronomy, v.35, p.739-746, 1943.

LOBATO, J.F.P. Sistemas intensivos de produção de carne bovina: 1. Cria. In: SIMPÓSIO SOBRE PECUÁRIA DE CORTE, 4., 1996, Piracicaba. Anais... Piracicaba: Fundação de Estudos Agrários Luiz de Queiroz, 1997. p.161-204.

LOBATO, J.F.P.; ZANOTTA JR., R.L.D.; PEREIRA NETO, O. A Efeitos das dietas pré e pós-parto na eficiência reprodutiva de vacas primíparas de corte. Revista Brasileira de Zootecnia, v. 27, n.5, p.857- 862,1998 .

LOBATO, J.F.P. A "vaca ideal" e o seu manejo em sistemas de produção de ciclo curto. In: SIMPÓSIO DA CARNE BOVINA: DA PRODUÇÃO AO MERCADO CONSUMIDOR, 1., 2003, São Borja. Anais... Porto Alegre: Universidade Federal do Rio Grande do Sul, 2003. p.9-43.

LOWMAN, B.G.; SCOTT, N.; SOMERVILle, S. Condition scoring beef cattle. Edinburgh: East of Scotland College of Agriculture, 1973. 8p.

MONTIEL, F.; AHUJA, C. Body condition and suckling as factors influencing the duration of postpartum anestrous in cattle: a review. Animal Reproduction Science, v.85, p.1-26, 2005

MOOJEN, E.L.; MARASCHIN, G.E. Potencial produtivo de uma pastagem nativa do Rio Grande do Sul submetida a níveis de oferta de forragem. Ciência Rural, v.32, n.1, p.60-65, 2002.

MORAES, A.; MARASCHIN, G.E. Pressões de pastejo e produção animal em milheto cv. comum. Pesquisa Agropecuária Brasileira, v.3, n.2, p.197-205, 1988

MORAES, A.A.S.; LOBATO, J.F.P. Efeito de duas épocas de desmama no desempenho reprodutivo de vacas de corte. Revista Brasileira de Zootecnia, v.22, n.6, p.1003-1011, 1993.

Moreno, J.A. Clima do Rio Grande do Sul. Porto Alegre: Secretaria da Agricultura, 1961. 41p.

MORRIS, C.A. Calving dates and subsequent intercalving intervals in New Zealand beef herds. Animal Production, v.39, n.1, p.51-57, 1984

MORRISON, D.G.; SPITZER, J.C.; PERKINS, J.L. Influence of prepartum body condition score change on reproduction in multiparous beef cows calving in moderate body condition. Journal of Animal Science, v.77, n.5, p.1048-1054, 1999.

MOTT, G.O.; LUCAS, H.L. The design conduct and interpretation of grazing trials on cultivated and improved pastures. In: INTERNATIONAL GRASSLAND CONGRESS, 6., 1952. Pensylvania. Proceedings... Pensylvania: State College Press, 1952. p.1380-1395.

NABINGER, C. Manejo e produtividade das pastagens nativas do subtrópico brasileiro. In:SIMPÓSIO DE FORRAGEIRAS E PRODUÇÃO ANIMAL, 1., 2006, Porto Alegre. Anais... Porto Alegre: Universidade Federal do Rio Grande do Sul, 2006. p.25-76.

NATIONAL RESEARCH COUNCIL - NRC. Nutrient requirement of beef cattle. Washington, D.C.: National Academy Press, 1996. 242p.

NICOLL, G.B. Influence of pre and post-calving pasture allowance on hill country beef cow and calf performance. New Zealand Journal of Agricultural Research, v.22, n.3, p.417-424, 1979.

NUÑES-DOMINGUEZ, R.; CUNDIFF, L.V.; DICKERSON, G.E. et al. Lifetime production of beef heifers calving first at two vs. three years of age. Journal of Animal Science, v.69, n.9, p.3467-3479, 1991.

PEREIRA NETTO, O.A.; LOBATO, J.F.P. Efeitos da ordem de utilização de pastagens nativas melhoradas no desenvolvimento e comportamento reprodutivo de novilhas de corte. Revista Brasileira de Zootecnia, v.27, n.1, p.60-65, 1998.

PIO DE ALMEIDA, L.S.; LOBATO, J.F.P.; SCHENKEL, F.S. Data de desmame e desempenho reprodutivo de vacas de corte. Revista Brasileira de Zootecnia, v.31, n.3, p.1223-1229, 2002.

PÖTTER, B.A.A.; LOBATO, J.F.P. Efeitos de carga animal, pastagem melhorada e da idade de desmame no comportamento 
reprodutivo de vacas primíparas. Revista Brasileira de Zootecnia, v.33, n.1, p.192-202, 2004.

PÖTTER, L.; LOBATO, J.F.P.; MIELITZ NETTO, C.G.A. Análises econômicas de modelos de produção com novilhas de corte primíparas aos dois anos, três e quatro anos de idade. Revista Brasileira de Zootecnia, v.29, n.3, p.861-870, 2000.

RESTLE, J.; PACHECO, P.S.; PASCOAL, L.L. et al. Efeito da pastagem, da produção e composição do leite no desempenho de bezerros de diferentes grupos genéticos. Revista Brasileira de Zootecnia, v.33, n.3, p.691-703, 2004.

REYNOLDS, W.L.; URICK, J.J.; KNAPP, P.W. et al. Maternal breed of sire effects on post weaning performance of first-cross heifers and production characteristics of two year-old heifers. Journal of Animal Science, v.69, n.11, p.4368-4376, 1991.

RIBEIRO, A.M.L.; LOBATO, J.F.P. Produtividade e eficiência reprodutiva de três grupos raciais de novilhas de corte. II. Desenvolvimento da progênie até o desmame. Revista Brasileira de Zootecnia, v.17, n.6, p.508-515, 1988.

RIBEIRO, E.L.A.; RESTLE, J.; ROCHA, M.A. et al. Eficiência produtiva em vacas primíparas das raças Aberdeen Angus e Charolês. Revista Brasileira de Zootecnia, v.30, n.1, p.125-132, 2001.

RICE, L.E. Nutrition and the development of replacement heifers. Veterinary Clinics of North America. Food Animal Practice, v.7, n.1, p.27-42, 1991.

ROCHA, M.G.; PILAU, A.; SANTOS, D.T. et al. Desenvolvimento de bezerras de corte submetidas a diferentes sistemas alimentares. Revista Brasileira de Zootecnia, v.33, n.6, p.2123-2131, 2004 (supl.2).
ROVIRA, J. Reproducción y manejo de los rodeos de cria: Montevideo: Hemisferio Sur, 1974. 293p.

ROVIRA, J. Manejo nutritivo de los rodeos de cria en pastoreio: Montevideo: Hemisferio Sur, 1996. 288p.

SAMPEDRO, D.; VOGEL, O.; CELSER, R. Entore a los 18 meses de edad. Evolución de peso y fertilidad de vaquillonas Hereford, Braford y cruzas originadas del cruzamiento alternado Hereford x Brahman. Corrientes: EEA INTA Mercedes, 2000. 4p. (Noticias y Comentarios, 336).

SANTOS, D.T.; ROCHA, M.G.; QUADROS, F.L.F. et al. Suplementos energéticos para recria de novilhas de corte em pastagens anuais. Desempenho animal. Revista Brasileira de Zootecnia, v.34, n.1, p.209-219, 2005.

STATISTICAL ANALYSIS SYSTEM - SAS. SAS/STAT user's guide: statistics. 4.ed. Version 6, Cary: SAS Institute, 1997. v.2, 943p.

SCAGLIA, G. Nutricion y reproduccion de la vaca de cria: uso de la condición corporal. Montevideo: INIA, 1997. 15p. (Serie Tecnica, 91).

SIMEONE, A.; LOBATO, J.F.P. Efeitos da lotação animal em campo nativo e do controle da amamentação no comportamento reprodutivo de vacas de corte primíparas. Revista Brasileira de Zootecia, v.25, n.6, p.1216-1227, 1996.

VIEIRA, A.; LOBATO, J.F.P.; TORRES JR., R.A.A. et al. Fatores determinantes do desempenho reprodutivo de vacas Nelore na região dos cerrados do Brasil Central. Revista Brasileira de Zootecnia, v.34, n.6, p.2408-2416, 2005 (sup1.).

WILM, H.G.; COSTELLO, D.F.; KLIPPLE, G.E. Estimating forage yield by the double-sampling methods. Journal of American Society of Agronomy, v.36, p.194-203, 1944. 